\title{
El framing (encuadre) de los líderes políticos durante el "Plebiscito por la Paz" en Colombia ¿Preparando la opinión pública para las elecciones 2018?
}

\begin{abstract}
Resumen
Los líderes políticos, como formadores de opinión especializados, jugaron un papel fundamental en la construcción de marcos interpretativos (frames) de la categoría paz para la campaña del "Plebiscito por la Paz" en Colombia (2 de octubre de 2016); proceso que derivó en una aproximación polisémica a esta noción, que luego se expresó en las urnas en una de las decisiones más reñidas en la historia del país, $50.22 \%$ votos a favor del No y 49.77 \% votos a favor del Sí. Este artículo presenta un análisis de los frames alrededor de la categoría paz que hicieron circular los líderes políticos en la opinión pública en medio del debate, para ello se realizó un rastreo durante el periodo entre el 18 de julio al 2 de octubre de 2016, de las noticias transmitidas por el diario El Espectador en su versión digital, bajo el descriptor "Plebiscito por la Paz". Estas noticias fueron codificadas de acuerdo a cinco frames: paz negativa, paz positiva, pax romana, paz liberal y paz imperfecta, esto permitió evidenciar el enfrentamiento ideológico enmascarado en la polisemia del frame paz, el cual por su ambivalencia estuvo al servicio de posiciones claramente contradictorias. Se concluye que, para el caso de análisis, la opinión pública no fue el escenario privilegiado para suplir déficits democráticos, ni mucho menos, para permitir la creación de consenso en espacios de disenso (Habermas, 1973); al contrario, los frames utilizados para la categoría paz generaron un proceso de polarización que posibilitó a los líderes políticos la creación de un imaginario adecuado a sus intereses individuales y de grupo, en pro del proceso electoral 2018.
\end{abstract}

\author{
Paula Andrea Valencia \\ Londoño \\ Ph.D. en Ciencias Sociales \\ Docente de la Universidad de \\ Medellín \\ Medellín- Colombia \\ Correo electrónico: \\ pvalencia@udem.edu.co \\ ๑1 orcid.org/0000-0002-1077-6959 \\ Google Scholar \\ Oscar Iván Muñoz Giraldo \\ Estudiante de la Maestría en \\ Conflicto y Paz \\ Asesor Jurídico Unidad de \\ Trabajo Legislativo Cámara de \\ Representantes, Colombia. \\ Correo electrónico: \\ mgoscarivan@gmail.com \\ ๑ orcid.org/0000-0002-9868-9648 \\ Google Scholar
}

Recibido: septiembre 04 de 2018 Aprobado: junio 15 de 2020

Palabras clave: paz, opinión pública, líderes políticos, líderes de opinión, teoría del encuadre, democracia, Plebiscito por la Paz. 


\section{The framing of political leaders during the "plebiscite for peace" in Colombia: Preparing Public Opinion for the 2018 Elections?}

\begin{abstract}
Political leaders, as specialized opinion shapers, played a fundamental role in the construction of interpretative frameworks of the peace category for the "Plebiscite for Peace" campaign in Colombia (2 October 2016). This process resulted in a polysemic approach to this notion which was later expressed at the polls in one of the most contested decisions in the history of the country, $50.22 \%$ of the votes in favor of "No" and $49.77 \%$ of the votes in favor of "Yes". This article presents an analysis of the frames around the "peace" category that political leaders circulated in the public opinion in the middle of the debate. To do this, a tracking of the news published by "El Espectador" newspaper in its digital version, under the descriptor "Plebiscite for Peace", was carried out during the period between July 18th and October 2 nd, 2016. These news were coded according to five frames: negative peace, positive peace, Pax Romana, liberal peace and imperfect peace. This codification allowed evidencing the ideological confrontation masked in the polysemy of the peace frame which, due to its ambivalence was clearly at the service of contradictory positions. It is concluded that, in this case, public opinion was neither the privileged setting to fill democratic deficits, nor to allow the creation of consensus in spaces of dissent (Habermas, 1973). Rather, the frames used for the peace category generated a polarization process that enabled political leaders to create an imaginary appropriate to their individual or group interests in favor of the 2018 electoral process.
\end{abstract}

Key words:

peace, public opinion, mass media, political leader, opinion leader, framing theory, democracy, Plebiscite for Peace. 


\section{Introducción}

En el marco del proceso de negociación entre el gobierno colombiano y las Fuerzas Armadas Revolucionarias de Colombia (FARC), y específicamente alrededor del Ilamado "Plebiscito por la Paz", circularon en la opinión pública difundida por los medios masivos de comunicación mensajes que daban cuenta de interpretaciones polisémicas sobre la categoría paz, las cuales respondían a los intereses electorales de los líderes políticos y a los vínculos estratégicos de los medios de comunicación. El resultado de esta ausencia de consenso fue el proceso de polarización que se expresó en las urnas en una de las decisiones más reñidas en la historia del país, 6.430 .170 votos a favor del No (50.22 \%) y 6.371 .911 votos a favor del Sí (49.77 \%); esto generó un impacto deslegitimador en el proceso de negociación, sus acuerdos, e incluso hoy, en las medidas para su implementación. De ahí la importancia de analizar los frames alrededor de la categoría paz que hicieron circular los líderes políticos en la opinión pública en medio del debate, y que permiten evidenciar el enfrentamiento ideológico (Pan y Kosicki, 1993) que enmascaró la polisemia del frame paz, el cual por su ambivalencia estuvo al servicio de posiciones claramente contradictorias.

En este artículo se analizan los mensajes sobre el "Plebiscito por la Paz" difundidos en El Espectador, diario digital de Colombia, por un tipo de formador de opinión especializado particular: los líderes políticos. Para ello, se utilizó una muestra significativa a partir del rastreo de los contenidos noticiosos relacionados con el descriptor "Plebiscito por la Paz" durante el periodo comprendido entre el 18 de julio y el 2 de octubre de 2016 (fecha de votación del Plebiscito).

Este rastreo permitió a su vez identificar los formadores de opinión especializados más relevantes en el contenido mediático: de un lado, 
la posición oficialista en cabeza del Presidente Juan Manuel Santos, los representantes de los Partidos de la Unidad por la Paz (Partido de la Unidad Nacional- Partido de la U, Cambio Radical, Liberal, Conservador, Partido Verde, Movimiento Alternativo Indígena y Social- MAIS y la Alianza Social Independiente- ASI), el Expresidente Cesar Gaviria y el jefe negociador con las FARC, Humberto de la Calle Lombana; de otro lado, la oposición representada por el Expresidente Álvaro Uribe Vélez, los líderes del partido Centro Democrático y el Expresidente Andrés Pastrana. Asimismo, se observaron posiciones intermedias en cabeza de líderes políticos regionales y de partidos de Centro, los Magistrados de las Altas Cortes, la Registradora Nacional de Estado Civil y el Consejo Nacional Electoral, los entes de control, los líderes de movimientos sociales y los académicos. La interpretación de los mensajes se hizo a la luz de cinco frames básicos: paz negativa, paz positiva, pax romana, paz liberal y paz imperfecta; cada uno como expresión de una apuesta teleológica y deontológica distinta en materia de las transformaciones que debía afrontar el país de cara a la firma del Acuerdo Final con las FARC.

Para dar cuenta del análisis, este artículo parte de un estado del arte sobre la aplicación de la teoría del framing al examen de los contenidos informativos alrededor de los temas de opinión pública y proceso de paz en Colombia, para luego introducir el papel de la opinión pública en el proceso democrático, con una salvedad importante, el rol sustancial que ocupa la opinión pública cuando a mecanismos de participación directa como el plebiscito se hace referencia. A continuación, se hace una rápida aproximación a los cinco frames comprendidos en el análisis, mencionando sus principales apuestas teleológicas y deontológicas. Posteriormente, en el apartado de análisis se realiza un recuento de los principales hallazgos del rastreo, siguiendo la estructura de los marcos propuestos. Por último, se presentan una serie de conclusiones, entre las cuales se destaca cómo las posiciones de los líderes políticos oscilaron entre las dos nociones extremas de paz: la paz positiva y la 
paz negativa; dejando por fuera de manera generalizada categorías intermedias y procesuales como la paz imperfecta. A la vez, se muestra cómo emergieron con fuerza otras subcategorías como la paz liberal y una posición pacificadora con visos de pax romana. En síntesis, se puede afirmar que cada actor político generó un imaginario alrededor del concepto de paz adecuado a sus intereses individuales y de grupo, en pro del proceso electoral 2018.

\section{Framing theory, proceso de paz en Colombia y opinión pública}

En la última década, los trabajos en materia de teoría del encuadre, marcos interpretativos o framing theory son bastos. Su origen se remonta a 1954 cuando Bateson incorpora la noción de frame en la psicología. Posteriormente, esta categoría también comienza a ser usada en la sociología a partir de los trabajos del Goffman (1986). Esta transición teórica determina su doble dimensión: psicológica y sociológica, lo que le da su carácter representativo y simbólico, y la convierte en puente entre pensamiento y realidad exterior (Sábada, 2001; Sábada, Rodríguez y Castro, 2012).

A partir de estos avances, el término pasa a ser incorporado al análisis de medios de comunicación gracias a Gitlin (1980) y su enfoque ideológico, y Tuchman (1983) y su sociología interpretativa; es allí cuando la doble condición de los frames (psicología y sociología) comienza a dar cuenta de la interacción de los medios con los niveles individual y social de la realidad (D'Angelo, 2002). En los años 90, la teoría es fortalecida por Entman (1993) al reconocer su carácter ecléctico y definirlo como un "paradigma fracturado". Para él, el framing es un recurso meta teórico sobre el cual debe construirse una declaración teórica general que demuestre su influencia en el pensamiento; sin embargo, sobrevienen las críticas. D’Angelo (2002), entre otros autores, argumenta que, debido a su pluralismo teórico y metodológico, el framing no debería afincarse como propone Entman (1993) en un único paradigma, sino 
en diversidad de ellos. Según el autor, los paradigmas orientadores del framing deben ser los endémicos a la comunicación: cognitivo, constructivista y crítico (D'Angelo, 2002).

Estas múltiples aproximaciones desde los medios de comunicación permiten que en los análisis sobre el framing sean identificables cuatro objetivos empíricos: 1. Identificar unidades temáticas Ilamadas frames, 2. Investigar los antecedentes de la producción de frames, 3. Identificar como esos nuevos frames activados inciden en la interpretación, demanda de información, toma de decisiones y evaluación, 4. Examinar como los nuevos los frames participan a nivel social en los procesos de generación de opinión pública y debate público (D’Angelo, 2002). Este último objetivo ligado a la orientación de este artículo.

Sin embargo, en el campo de los estudios para la paz, y de manera particular en materia de comunicación para la paz, el acercamiento a la teoría del framing es incipiente. Esto a pesar de la importancia que tiene el constructivismo en ambos campos del conocimiento: en la teoría del framing desde su premisa de la comunicación como constructora de la realidad (Tuchman, 1983; Berger y Luckmann, 1982; D'Angelo, 2002); en los Estudios de Paz, como visiones de una nueva realidad donde los valores prevalecen sobre la teoría (Galtung, 2003). Esta perspectiva constructivista permitiría realizar un símil, a partir del lugar que ocupan en la teoría, entre los frames y los valores de la paz: ambos serían principios ordenadores de carácter simbólico que dotan de sentido a la realidad social (Goffman, 1986, Reese, 2001). Además, como se observará en este artículo, los valores de la paz en el caso del "Plebiscito por la Paz" en Colombia se constituyeron en frames que orientaron la opinión pública hacia interpretaciones de la realidad social mediadas por posiciones ideológicas y orientadas por intereses político electorales. 
Esta incipiente incorporación del framing a los Estudios para la Paz, particularmente para el caso colombiano, es observable en las limitaciones que presenta la producción académica con que se cuenta sobre medios de comunicación y procesos de paz, la cual hace un acercamiento empíricoanalítico al tema y en el mejor de los casos crítico, dejando de lado la perspectiva constructivista. Su análisis sobre el carácter ordenador de la realidad social que generan los frames es tímido, y el contenido simbólico de la categoría paz con sus disputas ideológicas es abordado recurrentemente desde una perspectiva politológica y no comunicacional, con un marcado énfasis en el análisis de emociones políticas. Sin embargo, en el inventario reciente de producción científica alrededor del tema desde la perspectiva comunicacional cabe destacar algunos trabajos, entre ellos, el de Calderón (2014) sobre cobertura informativa frente al conflicto armado y el proceso de paz en Colombia, en él se afirma que la descontextualización y manipulación de las noticias creada por el lenguaje de los medios intensifica el conflicto armado. Por su parte, Guzmán (2015) y Richard y Saffon (2016), analizan el framing en torno a la paz en la campaña presidencial de 2014; Guzmán (2015) demuestra cómo la agenda mediática y los frames de esta campaña estuvieron alineados con las apuestas del en ese entonces Presidente Juan Manuel Santos para dar continuidad a las negociaciones de paz, lo que da muestra de que "en un sistema mediático polarizado como el colombiano, los medios siguen siendo un actor político que atiende a intereses partidistas" (Guzmán, 2015, p. 7). En contraste, Richard y Saffon (2016) concluyen que el frame confrontación domina los contenidos, y los frames propuestas de paz y narración son usados para definir antagonismos entre los candidatos.

Específicamente en materia de opinión pública y proceso de paz con las FARC, es de destacar el análisis de Cárdenas (2013) sobre actitudes e imaginarios de los bogotanos frente al proceso de paz, según afirma el autor, los "esfuerzos comunicativos de los directamente involucrados no han sido suficientes para 
generar un ambiente político positivo que legitime el proceso" (p. 54) pues el control del mensaje se ha dejado a la construcción autónoma de los medios y los actores de oposición, lo que reduce los niveles de credibilidad, confianza y aceptación del proceso.

En relación directa con el "Plebiscito por la Paz", Ríos, Pérez y Morillo (2018) analizan la incidencia de la agenda setting ${ }^{1}$ en Facebook alrededor de los ejes del Acuerdo Final con las FARC, previo a la votación. De esto concluyen que "hay una relación estadísticamente significativa entre la entidad que fija la agenda y las variables de la agenda (...) las acciones de dar like y share no estuvo influenciada por el tema de la agenda, pero sí por la entidad que la fija" (p. 93). Por su parte, Acosta, Brunet y Córdoba (2017) analizan, con base en las fuentes de información y los géneros periodísticos utilizados, la calidad de la información sobre el "Plebiscito por la Paz" emitida por el elespectador.com, ellos concluyen que existe una baja calidad periodística, basada en un periodismo de declaraciones que redunda en una opinión pública mal informada.

En el campo politológico se destaca un grupo de trabajos sobre "Plebiscito por la Paz" y emociones políticas, entre los que se encuentran el trabajo de Perilla (2018) quien analiza las emociones políticas que circularon en redes sociales posplebiscito por la paz y que impulsaron la acción colectiva para el rescate de los Acuerdos, logrando conformar desde el ciberespacio un "campo político" (Perilla, 2018, p. 178). En esta misma línea se encuentra el trabajo de Cardona-Zuleta y Londoño-Álvarez (2018) sobre "La retórica del miedo como estrategia política"; el eje de este análisis son las intervenciones previas a la votación de Juan Manuel Santos y Álvaro Uribe Vélez, y del gerente del Comité Promotor Nacional por el No, Juan Carlos Vélez Uribe, posplebiscito.

\footnotetext{
1 La Agenda Setting se puede definir como la forma en que la agenda mediática determina la agenda pública, y, por tanto, la percepción del público sobre los temas de mayor relevancia (McCombs y Shaw, 1972), es un concepto par del framing y en los primeros años de construcción teórica, existía una suerte de indistinción entre ellos.
} 
Concluyen los autores que el miedo fue el influenciador del voto aprobatorio o desaprobatorio de los acuerdos, a partir del uso instrumental que hicieron de él los actores políticos.

Esta perspectiva de análisis de la incidencia de las emociones políticas en la formación de opinión publica obliga a hacer un acercamiento a un elemento que estaba en el centro del debate de la votación del "Plebiscito por la Paz" y que, a pesar de no ser el foco de atención de este artículo, es importante tener presente. Este fue el rol jugado por las iglesias cristianas y líderes políticos conservadores, a partir del debate sobre la mal Ilamada "Ideología de Género" que supuestamente permeaba una cartilla publicada por el Ministerio de Educación Nacional en cumplimiento de una sentencia de la Corte Constitucional, y que pretendía fomentar la construcción de ciudadanía y la convivencia con base en el respeto a la igualdad. Las duras críticas a dicha propuesta, entre las que estuvieron las recurrentes declaraciones del Exprocurador Alejandro Ordoñez "están utilizando la paz como excusa para imponer la ideología de género" (El Espectador, 26 de septiembre de 2016), se convirtieron en mecanismo de presión política frente al gobierno nacional y, en particular, en comodín para el apoyo o no al plebiscito. En tal sentido, Botero (2017) y Cardona-Zuleta y Londoño-Álvarez (2018) coinciden en reconocer el peso que tuvieron en el apoyo a la campaña del No la derecha conservadora y los grupos cristianos, quienes movilizaron "según cuentas de los promotores, un millón de votos por el NO" (Córdoba, 1 de junio de 2017) a partir de una estrategia emotiva basada en el miedo a una "ideología de género" que incitaba a la homosexualidad, caso que sería catalogado incluso como postverdad (Córdoba, 1 de jun de 2017). Sin embargo, Basset (2018) invita a matizar la afirmación del voto cristiano como elemento decisivo en la victoria del No. 
En relación con la producción posterior al plebiscito que analiza su impacto sobre el proceso electoral 2018 y la implementación del Acuerdo Final, desde la agenda setting de medios de comunicación como la Revista Semana, Valencia y Ríos (2020) analizan los procesos cíclicos de repunte y descenso en la importancia de los temas de peacebuilding y statebuilding previo a la primera vuelta de la elección presidencial 2018; frente a lo que concluyen que, en consonancia con las afirmaciones de los artículos precedentes en materia de emociones políticas, el manejo periodístico y la priorización que hizo la Revista Semana estuvo dirigido a cuestionar la fragilidad del Acuerdo y su implementación, haciendo énfasis en temas de seguridad y el rol de la ley, lo cual sirvió de caja de resonancia de las propuestas de los candidatos que buscaban construir su imagen desde el distanciamiento con el proceso de paz.

Sumado a las limitaciones antes expuestas, sobre lo que Goffman (1986) Ilama efecto del framing, es decir, sobre la construcción de marcos de interpretación o frames sobre el Acuerdo de Paz y específicamente, el "Plebiscito por la Paz", como se logra observar son pocas las investigaciones existentes en Colombia. Sin embargo, para el caso de estudio, el efecto del framing es un campo de investigación de importancia, máxime si se tienen en cuenta los efectos que pueden tener los medios de comunicación sobre la formación de la opinión pública. Más allá de la creación de agendas, el framing, en función de los marcos de interpretación que establece, determina "las voces autorizadas y fuentes más confiables o 'reputadas' para hablar de los temas de la agenda" (Cárdenas, 2013, p. 46). En este caso, esas voces autorizadas serían los partidos, quienes establecen los términos de la discusión, a partir de proveer una (re)definición específica del problema, una interpretación causal del mismo o evaluaciones morales de este (Entman, 1993). Es por ello que se hace necesario identificar estos frames y las voces autorizadas en relación con el "Plebiscito por la Paz" como primer paso para reconocer los márgenes de esa deliberación pública, los apoyos que atrajo, la movilización de la acción 
colectiva y su influencia finalmente en la opinión pública (Valera-Ordaz y López-García, 2014; Tankard, 2001; Pan y Kosicki, 1993).

La opinión pública engloba múltiples fenómenos en muchos casos diversos, pero entre ellos, una de sus funciones principales es suplir los déficits democráticos y permitir la creación de consensos en espacios de disenso; entre otros mecanismos, a través de las tareas de crítica y de control (Habermas, 1973, p. 61). Aquí entran a jugar un rol primordial los medios de comunicación quienes, en un estado de cosas ideal, como afirma Farias para el caso del proceso de transición español, serían "elementos indispensables para medir el grado de democracia de un sistema político" (1999, p. 71). Sin embargo, sobre ellos recaen todas las influencias políticas del entorno, esto debido a que "el éxito de los partidos depende de la opinión de los ciudadanos, más que de los militantes y de las afiliaciones partidistas históricas del electorado, los instrumentos de formación de la opinión pública se vuelven cruciales para el éxito electoral" (Valera-Ordaz y López-García, 2014, p. 42). Es allí donde emerge un engranaje fundamental en su mecánica, los formadores de opinión privilegiados (propietarios de los medios y líderes políticos), quienes cumplen, aun hoy en el caso colombiano, como diría Sartori (2009), el rol de "iluminar" sobre los asuntos públicos que están vinculados a sus intereses políticos.

Desde la perspectiva de los marcos interpretativos, estos líderes de opinión especializados, en particular los líderes políticos que son quienes interesan a este análisis, como afirma Goffman (1986), estructuran los marcos que definen el contexto y los esquemas que permiten apropiar los datos externos objetivos; apuntalados en el importante rol atribuido desde el framing a los medios de comunicación como generadores de marcos sociales que reproducen la posición hegemónica (Gitlin, 1980). Es así como estos líderes políticos integrarían, a través de su función como formadores de opinión especializados, marcos de acción colectiva y periodísticos, representando en un solo proceso 
la función significativa noticiosa y la movilizadora ideológica (Sádaba, 2001), lo que daría mayor legitimidad a su enfoque interpretativo, desde la perspectiva de objetividad, que entrona el ejercicio periodístico.

No obstante, cada vez es más recurrente que los frames impulsados por estos líderes de opinión especializados incorporen la negative campaigning (campaña negativa), es decir una presencia del ataque permanente al rival político, la cual es un arma eficaz para captar la atención pública (y mediática) (Valera-Ordaz y López-García, 2014). Esto es lo que se pudo observar en la Campaña del NO que, según declaraciones de su Gerente Juan Carlos Vélez al periódico La República, utilizó una estrategia que "había consistido en alentar la inconformidad de los electores propagando interpretaciones tergiversadas del contenido de los Acuerdos, pensadas en función de públicos específicos" (Ramírez, 4 de octubre de 2016). Sus declaraciones tuvieron eco también en otros medios masivos de comunicación como el periódico El Colombiano que tituló: "Estábamos buscando que la gente saliera a votar verraca" (El Colombiano, s.f.) y El Espectador que titularía: "La cuestionable estrategia de campaña del No" (El Espectador, 6 de octubre de 2016).

Estos públicos específicos de los que hablaba Juan Carlos Vélez fueron, entre otros, según Basset (2018), votantes de sectores populares, zonas periurbanas y ciudades intermedias, no identificadas con el uribismo ${ }^{2}$, hacia quienes se dirigió una campaña del voto por NO. El eje de esta campaña giró en torno a la desatención del Gobierno a las zonas no afectadas directamente por el conflicto armado, lo que los hizo sentir como "los olvidados de la paz" (Basset, 2018, p. 263) y reforzó sus temores frente a la supuesta impunidad que propiciaba el Acuerdo y los incentivos perversos que otorgaba a la actividad criminal, al conocerse en el último punto de la agenda los estímulos económicos para el proceso de reinserción. Esta sensación de impunidad, sumada al hermetismo 
que caracterizó la negociación (Botero, 2017), fueron los factores que capitalizó la negative campaigning.

Sin embargo, frente a los efectos de esta negative campaigning en la votación favorable hacia el No existe un debate entre los diversos autores sobre el peso de las emociones políticas. Por ejemplo, Botero afirma que "Los partidarios del No diseñaron una campaña que buscaba generar rechazo e Indignación" (2017, p. 378), sin embargo, Basset asegura que "mal se haría en atribuir la victoria del $\mathrm{NO}$ a brotes de irracionalismo o a la influencia nefasta de una campaña engañosa" (2018, p. 263). Apartándose de dicho debate, este artículo se centrará en el enfrentamiento ideológico (Pan y Kosicki, 1993) que enmascara la polisemia del frame paz y que permitió, por su ambivalencia, estar al servicio de posiciones claramente contradictorias.

Teniendo en cuenta los determinantes anteriormente descritos, podría afirmarse que la opinión pública en Colombia, como ejercicio de la democracia (Sartori, 2009) es frágil e incompleta, al ser solo un reflejo de los símbolos y valores (Janowitz, 1994 citado en Farias, 1999) que cimientan los marcos interpretativos propagados por los formadores de opinión privilegiados. Esto genera limitaciones cualitativas para su función electoral, las cuales pueden ser compensadas en el ejercicio de la democracia representativa debido a su baja vinculación en la toma de decisiones, pues se limitaría a elegir a sus representantes (Sartori, 2009). Sin embargo, ¿qué pasa cuando esa opinión pública se expresa en un ejercicio electoral de democracia participativa, como ocurre en el caso del plebiscito? Aquí, el demo no elige sus representantes, sino que toma decisiones sobre lo fundamental.

A esta problemática se suma la paulatina desaparición del interés general soportado en la conciencia racional, en función del favorecimiento de "la auto presentación publicista de intereses privados" (Habermas, 1981, p. 222). 
En el "Plebiscito por la Paz", como se verá más adelante, los conceptos de paz circulantes fueron puestos en la esfera pública por formadores de opinión especializados, en este caso líderes políticos, quienes acogieron una u otra forma de aproximarse a la noción de paz en función de la conveniencia con sus intereses privados, desde el supuesto de este artículo, intereses vinculados al proceso electoral 2018; esto en consonancia con el principio de la opinión pública como expresión de la tensión de fuerzas de poder (Bourdieu, 1992). Este sistema de fuerzas y los imaginarios políticos que gravitaron alrededor del frame paz en la coyuntura del "Plebiscito por la Paz", y que hasta hoy tienen efecto, serán pues el centro de atención de los análisis y conclusiones que se verán más adelante.

\section{Las múltiples categorías de paz presentes en los discursos políticos previos al plebiscito: un acercamiento teórico}

En consonancia con Bateson (1972), el marco de referencia se constituye en elemento clave para interpretar la realidad exterior; en el caso particular del "Plebiscito por la Paz" se crearon múltiples marcos de referencia que derivaron en variadas interpretaciones de la realidad del proceso y diferentes alcances en materia deontológica y teleológica, dando cuenta, como afirma Luntz (2007) (citado en Sábada, et al. 2012), de la batalla política como una guerra de palabras que, en función de las elegidas, pueden transportar a los receptores a universos discursivos que resulten de interés o, al contrario, que lleven a modos de pensar del enemigo político. A continuación, se hace una aproximación a los cinco frames seleccionados en materia de paz, el peso de la carga simbólica otorgada a cada concepción de paz en la movilización de los votantes y su alcance en relación con el Acuerdo Final con las FARC.

La paz es una categoría analítica rastreable desde los albores del surgimiento de lenguaje que cuenta con una elevada elaboración. La paz del Egipto 
faraonio y la eirene griega son dos de los referentes que permiten que la antigua Roma cree un concepto de paz con alcance en lo personal, en la República y en el imperialismo; en este último ámbito es donde se asienta el concepto de pax romana en su concepción más generalizada hoy. La actualización de las teorías políticas y del derecho internacional que exigió la expansión territorial del Imperio Romano lo obligó a buscar cómo minimizar los costos del imperialismo, y para ello diseñó una política de inclusión traducida en tratados y leyes, donde la pax sería el camino para aminorar o regular la violencia impuesta por el Imperio (Muñoz, 1998). Hoy dicha pax se resume en un concepto ligado al mantenimiento del status quo y el orden social, lo que ha permitido, por ejemplo, a Palacios y Serrano (2010) denominar Pax Priista al modelo centralista de pacificación que se produjo en México durante los más de 40 años de presencia en el poder del Partido Revolucionario Institucional (PRI) y que permitió contener la expansión del mercado interno de drogas y el acceso de los narcotraficantes a la participación abierta en el poder político; también se ha usado el termino para denominar Pax Uribista al proceso de pacificación realizado por el Expresidente Alvaro Uribe Velez en Colombia en sus ocho años de mandato.

En su concepción contemporánea, la paz, en su tránsito a objeto de estudio científico de las ciencias sociales, comienza sus construcciones de sentido posterior a la Segunda Guerra Mundial, por lo tanto, se encuentra atada claramente al devenir histórico del siglo XX, no solo en relación con las confrontaciones armadas, sino también desde el comportamiento de las relaciones internacionales y el desarrollo. Es por ello que, en una primera etapa post Segunda Guerra Mundial, en el afán de prevenir el resurgimiento de una guerra similar a las dos que habían aquejado al mundo en la historia del siglo $X X$, surge una primera aproximación a la paz desde una perspectiva de negación, una paz que era la antítesis de la violencia, y en forma particular de la guerra. Esta fue Ilamada por teóricos como Galtung (2003) una paz 
negativa, una paz que sería leída como ausencia o reducción de todo tipo de violencia, y que tiene la violencia como su referente de interpretación.

Superada esa coyuntura crítica en materia de confrontación armada directa, la reflexión en la década del 70 giró alrededor de la relación entre desarrollo y ser humano, con el fin de superar las ideas previas de desarrollo como crecimiento económico. A la par de esta transformación del objeto de estudio del desarrollo, surge una nueva concepción de paz: la paz positiva, expresión de un segundo momento en los estudios para la paz, donde la categoría paz trasciende el concepto de paz negativa, para centrarse en una paz pensada desde una perspectiva de justicia social. Es una paz interpretada desde la transformación creativa y no violenta del conflicto "presencia de simbiosis y equidad en las relaciones humanas, (....), equivalente a ausencia de violencia estructural y cultural" (Galtung, 2003, p. 37), una paz que, sin embargo, tiene múltiples detractores por su carácter altamente ambicioso y para muchos, bastante utópico.

Por esta razón, construcciones posteriores buscan acercarse a otras conceptualizaciones de paz que permitan concebirla como un proceso y no solo como un fin en sí mismo. Para ello, diversos actores plantean nuevas posturas, entre ellas la paz imperfecta propuesta por Muñoz (s.f.); esta aproximación comprende la paz como "todas estas experiencias y estancias en la que los conflictos se han regulado pacíficamente, es decir en las que los individuos y/o grupos humanos han optado por facilitar la satisfacción de las necesidades de los otros, sin que ninguna causa ajena a sus voluntades lo haya impedido" (p.14). La paz entendida como proceso abre la puerta para la generación de una serie de estrategias que permiten la participación de los actores sociales en la consolidación de una cultura de paz, desde una perspectiva de interculturalidad, haciendo a los sujetos artífices de su desarrollo, y legitimadores de la paz cultural. 
Sin embargo, a la par de la construcción teórica del objeto de estudio de las ciencias de paz, existe todo un desarrollo institucional al respecto; desarrollo que tiene sus antecedentes en las operaciones de paz de Naciones Unidas durante Guerra Fría, con dos acciones básicas: Peace Keeping y Peace Making (Paris, 2005) pero que se concreta post Guerra Fría, en respuesta a las esperanzas de paz de aquel momento, presentando como estandarte fundamental de su construcción el documento An Agenda for Peace (1992) elaborado por el Secretario General en ese entonces de Naciones Unidas, Boutros Ghali.

Sin entrar en detalle sobre las coincidencias y diferencias entre la propuesta institucional de paz de Naciones Unidas y construcciones de paz operativas que datan su origen desde el liberalismo clásico y luego tuvieron desarrollo con las propuestas de Wilson a principios del siglo XX; la aproximación operativa más conocida hoy en materia de paz es la Paz Liberal, una paz que sienta sus postulados en el liberalismo clásico, pero los reedita al contexto actual de una economía globalizada. Su postulado básico es: "Ios estados democráticos rara vez van a la guerra", postulado que, como dice Paris (2005), surge de un consenso académico que emergió en occidente en la década de los ochenta, y que gira en torno a la conveniencia de la democracia para la construcción de paz.

Boutros Boutros-Ghali, artífice de An Agenda for Peace en 1992 (Citado por Paris, 2005), describiendo los beneficios de la democracia en países devastados, dijo que

la democracia fomenta la evolución del contrato social sobre el cual una paz duradera se puede construir [y] es el único medio a largo plazo para arbitrar y regular muchas tensiones políticas, sociales, económicas y étnicas que constantemente amenazan con desgarrar las sociedades y destruir los estados. (p. 45) 
Hoy la Paz Liberal cobra aún más vigencia al concebirse la economía de libre mercado y la democracia liberal (con su especial énfasis en el reposicionamiento de la función electoral) como modelo político y económico preponderante, en expansión a partir de los procesos de paz post Guerra Fría y en consolidación a través del mercado Global. Esto sin desconocer las apuestas de la corriente crítica de los estudios de paz que aboga por un modelo de paz post liberal (Richmond, 2011).

Como se puede ver en este rápido recorrido por el concepto de paz, existe una amplia gama de posibilidades en cuanto a esta categoría se refiere, desde apuestas poco exigentes pero utópicas, como la ausencia de violencia, hasta transformaciones estructurales que lleven a la justicia social, pasando por paces que revalorizan los procesos de construcción constante de paz, y paces que buscan la expansión del libre mercado a través de la universalización del modelo democrático. Sin embargo, todo ello abrigado por la etiqueta de paz, una paz que no cuenta con consenso, es más, donde el disenso, como diría Galtung (2003) es la única alternativa para no producir la violencia simbólica que implica la imposición de una teoría.

\section{Método}

El artículo se estructura a partir de los hallazgos del rastreo de los contenidos noticiosos relacionados con el descriptor "Plebiscito por la Paz" durante el periodo comprendido entre el 18 de julio y el 2 de octubre de 2016 en la versión digital del diario El Espectador. Se asumió como unidad de análisis la noticia, apropiando la perspectiva de Tuchman (1978) de entender la noticia como un modo de conocimiento. Se recolectaron 85 elementos relacionados con el código de rastreo. Se eligió este medio de comunicación por su amplia cobertura regional y sectorial, la diversidad de posiciones políticas en él representadas y, como afirman Acosta et al. (2017), por ser un medio que se 
dedicó a reproducir declaraciones de los líderes políticos, siendo una vitrina privilegiada para analizar este formador de opinión especializado en particular.

Para el análisis se utilizaron los cinco frames ya mencionados: paz negativa, paz positiva, pax romana, paz liberal y paz imperfecta, los cuales sirvieron de pre codificación por medio del software Atlas TI.

\section{Análisis y resultados}

Como se mencionó, los frames seleccionados fueron aplicados a 85 hechos, de estos 38 artículos fueron codificados bajo el frame paz negativa, siendo este el marco interpretativo que tuvo mayor protagonismo. La paz negativa es un claro reflejo del enfrentamiento ideológico que puede generar el framing como afirman Pan y Kosicki (1993), pues motiva dos marcos de interpretación del "Plebiscito por la Paz", uno que permite cuestionar la eficacia de los Acuerdos como mecanismo para la finalización del conflicto armado, y otro que lo concibe como un medio para alcanzar una paz estable y duradera. Esto en una suerte de continuidad con lo hallado por Guzmán en el análisis de los frames de las elecciones presidenciales 2014, según la autora, "Por un lado, se identifica el frame que busca trasladar a los colombianos la oportunidad que representa el proceso de paz promovido por el gobierno de Juan Manuel Santos, y por otro, nos encontramos frente a un marco que define las negociaciones como un acto de rendición del gobierno a las FARC.EP" (2015, p. 124).

Por tanto, los efectos del uso de este frame fueron ambivalentes. Desde los impulsores el voto por el SI se resaltaba la importancia del fin del conflicto con las FARC y del acallamiento de los fusiles para conseguir condiciones plenas de paz. Los impulsores del voto por el No, desde una perspectiva de negative campaigning, afirmaban por su parte que para garantizar el fin de la guerra debía volverse a negociar el Acuerdo, limitando las concesiones a las 
FARC e impulsando un proceso de sometimiento. Esta propuesta se convirtió en eje de campaña para las elecciones presidenciales del 2018 con frases como "el primer desafío del Centro Democrático será el de volver trizas ese maldito papel que Ilaman el acuerdo con las FARC", frase pronunciada en mayo de 2017, durante la Convención Nacional del Centro Democrático por Fernando Londoño, en su momento Director Honorario de ese partido político (Semana, 5 de agosto de 2017). Dicha frase luego fue matizada, pero describe claramente el tránsito del encuadre de la paz negativa a la pax romana que se analizará adelante.

Entre las voces autorizadas que utilizaron el marco de paz negativa para apoyar el Sí se encontraban, además del gobierno en cabeza del presidente Juan Manuel Santos y el negociador de paz Humberto de la Calle Lombana, el Expresidente Cesar Gaviria; igualmente agremiaciones como FECODE, los pastores cristianos, los integrantes de los partidos políticos de la Unidad por la Paz y los ex paramilitares en extradición o que ya purgaron la pena.

Ahora bien, el haberse gestado una unidad de partidos para apoyar el "Plebiscito por la Paz" y la negociación en la Habana no significó una garantía para la construcción de un solo discurso. Cada uno, desde sus intereses políticoelectorales, promovía bajo diferentes marcos interpretativos la votación por el Sí. Es el caso de los directivos del Partido de la U quienes usaron el eslogan: "Sí a la paz, No a la guerrilla" (El Espectador, 21 de julio de 2016); el Expresidente Cesar Gaviria que sostenía: "votar NO, es votar por la Guerra" (El Espectador, 3 de agosto 2016), o la senadora Claudia López bajo el slogan: "Sí a la paz y adiós a las Farc" (El Espectador, 5 de agosto de 2016). Esto da cuenta de la relación entre frames y cultura de la que hablan Van Gorp (2007), Entman (2007), Lakoff (2008); "cuanto más congruentes sean los frames con ella, más posibilidades tienen de influir en la audiencia" (Sábada, Rodríguez y Castro, 2012, p. 118), y lamentablemente Colombia construyó una "memoria 
colectiva compartida" (Van Gorp, 2007) a partir de un imaginario guerrerista donde se ubicó a la guerrilla en el arquetipo del enemigo.

Además de en las campañas de cada posición, el frame paz negativa se observó en noticias relacionadas con el cese al fuego y la firma del acuerdo como los reportes sobre el momento para la firma, los ataques sufridos por algunos personajes en sus diferentes campañas, la inscripción de las campañas, el trabajo de la Registraduría Nacional del Estado Civil con el fin de garantizar la votación del 2 de octubre de 2018, las diferentes demandas que se interpusieron como estrategia para frenar las votaciones, los condicionantes de los partidos y la forma como se comportaban las encuestas a medida que se iba acercando la fecha para la votación. Todas estas noticias tenían como norte el fin de la guerra, una vez se llevaran a cabo los comicios.

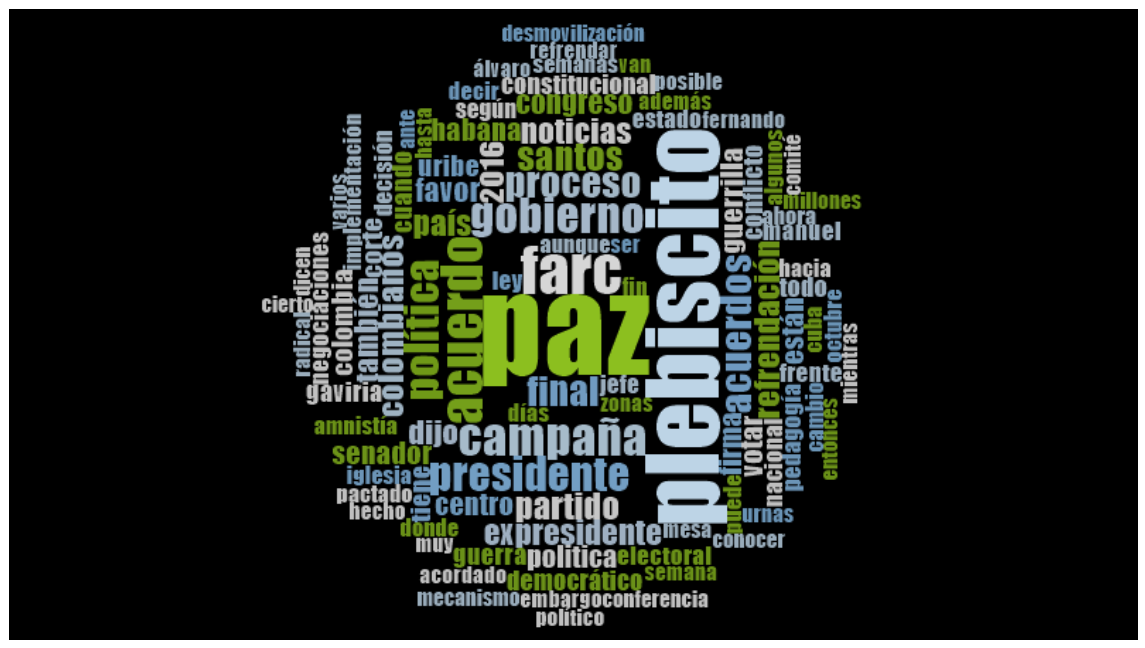


La paz Liberal ocupó el segundo renglón en materia de marcos interpretativos, 27 artículos estuvieron relacionados con el tema; es importante anotar que este frame comprendió valores liberales tanto económicos como políticos, sujeción a normas legales, el fortalecimiento institucional como soporte de la democracia, el estado de derecho y el libre mercado. Los hechos noticiosos que adoptaron este marco interpretativo partieron de la posición que emitían los presidentes de las altas Cortes, la Misión de Observación Electoral, el Consejo Nacional Electoral, la Registraduría Nacional del Estado Civil y la Procuraduría General de la Nación.

En cuanto a las voces autorizadas, igual que en el frame paz negativa, el presidente Juan Manuel Santos es uno de los promotores de este marco interpretativo, esto a partir de resaltar la importancia económica del fin del conflicto para el país en materia de inversión extranjera directa y turismo, además de promover la participación electoral en la votación del plebiscito. Según afirmaba el mandatario, en esta jornada histórica los colombianos decidirán el futuro del país: "Mañana cada colombiano tendrá el mismo poder que el presidente de decir sí o no" (El Espectador, 1 de octubre de 2016). Esto en consonancia con los esfuerzos de Colombia para ingresar a la OCDE.

Otros hechos noticiosos relacionados con fortalecimiento institucional y régimen electoral dieron cuenta de este frame como lo fue la propuesta de realizar el plebiscito de manera digital en aquellas regiones de difícil acceso (El Espectador, 10 de agosto de 2016), los ejercicios de pedagogía respecto a lo que significaba el plebiscito (El Espectador, 19 de julio de 2016), los costos de la jornada electoral, o el proceso de convocatoria para la votación (El Espectador, 19 de julio de 2016). 


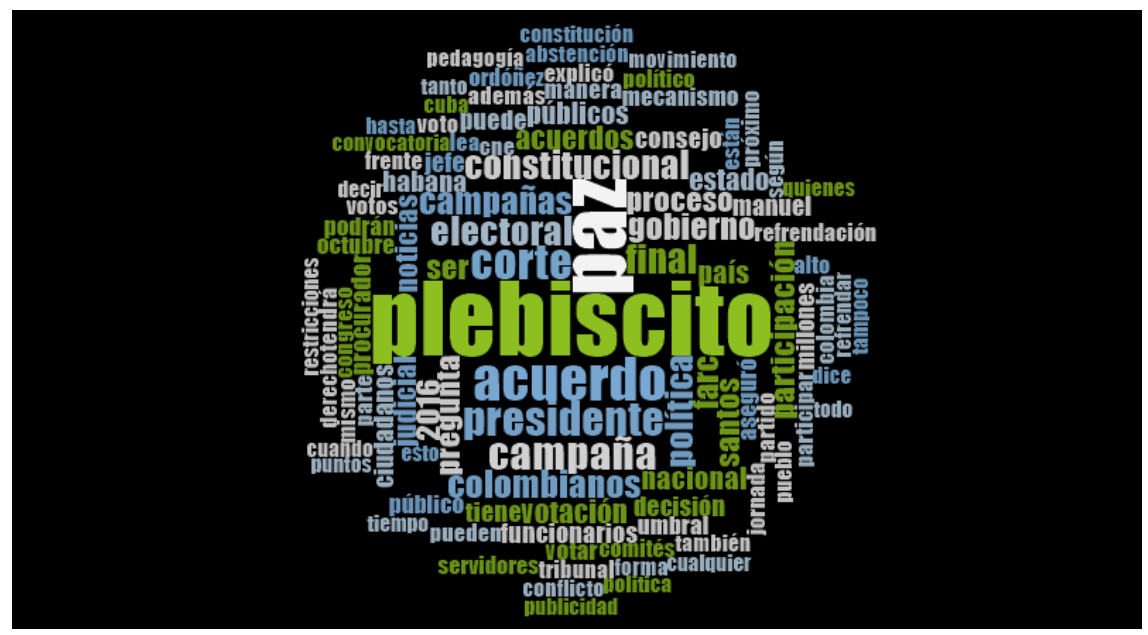

Imagen 2. Nube de palabras Paz Liberal Fuente: elaboración propia a través del software NVivo.

La Paz Romana fue en su orden el tercer frame más utilizado con $\mathbf{1 1}$ hechos noticiosos que coinciden con su interpretación; los militantes del partido Centro Democrático fueron los líderes de opinión que recurrieron en mayor medida a este encuadre. Entre los principales tópicos que se abordaron desde este frame están los argumentos y estrategias para fomentar la abstención y el voto por el NO con consignas como "El No también es la defensa de la paz" (El Espectador, 1 de octubre de 2016). También se dio cubrimiento a las acciones legales de esta colectividad para suspender el plebiscito (El Espectador, 5 de septiembre de 2016; 30 de septiembre de 2016). Líderes políticos como el Expresidente Andrés Pastrana afirmaron que el plebiscito era "un golpe de Estado contra la constitucionalidad y la legalidad", invitando al partido conservador a votar por el No (El Espectador, 28 de julio de 2016). También se emitieron constantes mensajes sobre el plebiscito como "claudicación al terrorismo", 
la "venezolanización" del país, o la expansión del "castrochavismo" (Jiménez, 28 de agosto de 2016). Las alianzas a favor del No se prologaron y fortalecieron en el proceso electoral 2018, destacándose el liderazgo de los Expresidentes Alvaro Uribe y Andrés Pastrana sobre la base de la recuperación del orden democrático.

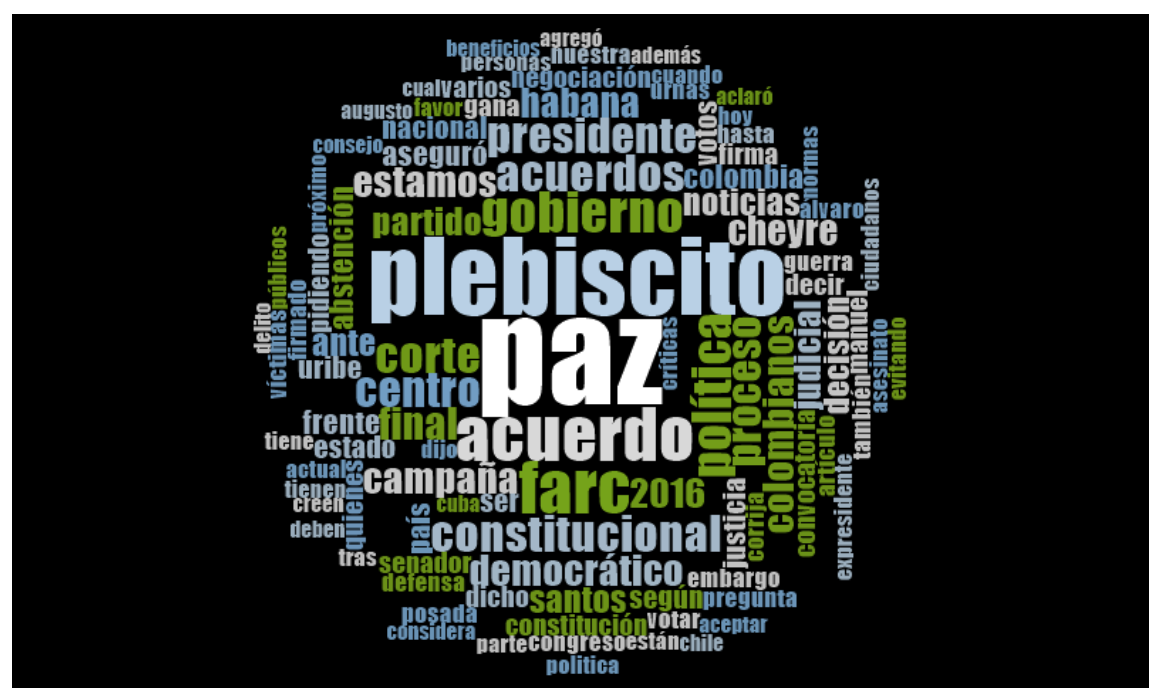

Imagen 3. Nube de palabras Pax Romana. Fuente: elaboración propia a través del software NVivo.

La Paz Positiva sigue en su respectivo orden con ocho hechos noticiosos enmarcados en esta interpretación, entre ellos, el respaldo que los diferentes gobernadores del país dieron al gobierno nacional para apoyar el "Plebiscito por la Paz", en aras de llevar desarrollo, un mejor presente y futuro para las regiones (El Espectador, 1 de agosto de 2016); los movimientos sociales que de manera alternativa adelantaron acciones pedagógicas, noviolentas y pacifistas 
a favor del Sí, con la premisa de que el fin del conflicto traería consigo justicia social, igualdad y equidad (El Espectador, 4 septiembre de 2016); el discurso de las subregiones sobre las bondades de la paz (El Espectador, 5 de septiembre de 2016); la posición de los académicos del país (El Espectador, 10 de agosto de 2016); y la iglesia católica a favor del Sí, a partir de las múltiples posibilidades que traería para el desarrollo el país (El Espectador, 18 de agosto de 2016). El respaldo de las regiones por el Sí, con su esperanza de cambio, se vio representado geográficamente en una relación centro-periferia en la votación del plebiscito, demostrando un comportamiento similar al de la elección presidencial de 2014, y que se ve replicado en la votación favorable al centro y la izquierda en la primera ronda de las acciones presidenciales de 2018.

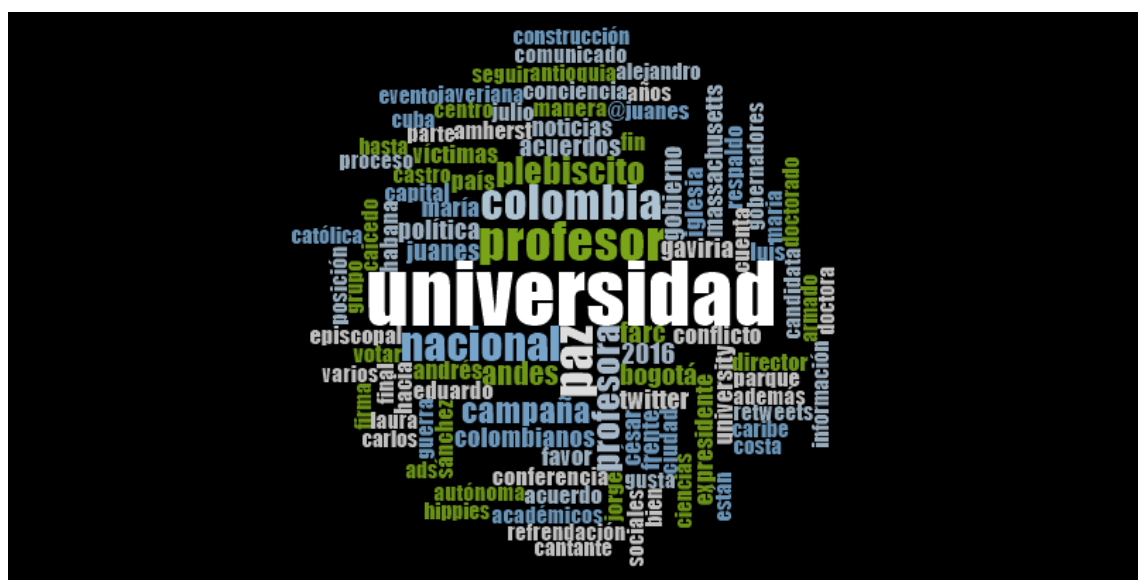

Imagen 4. Nube de palabras Paz Positiva Fuente: elaboración propia a través del software NVivo.

El frame paz imperfecta solo fue rastreable en un artículo sobre la estrategia del Exalcalde de Bogotá Antanas Mokus para promover el "Plebiscito por la Paz" 
preparándose para la etapa del posconflicto desde un proceso de inclusión social de los desmovilizados como garante de la vida (El Espectador, 25 de julio de 2016), esto a pesar de que el concepto paz imperfecta fue utilizado de forma reiterada no desde su carácter procesal sino para describir las debilidades del Acuerdo.

\section{Conclusiones}

El "Plebiscito por la Paz" en Colombia es la muestra fehaciente de los efectos sobre la democracia electoral de una opinión pública fragmentada e incompleta, pero destinada a la toma decisiones de fondo sobre cuestiones fundamentales a partir de marcos interpretativos construidos por líderes de opinión que, en detrimento del interés general, legitiman con el uso de medios masivos de comunicación el proceso de "auto representación publicista" (Habermas, 1981) de sus intereses privados. En tal sentido, para el caso de análisis, la opinión pública no fue el escenario privilegiado para suplir déficits democráticos, ni mucho menos, para permitir la creación de consenso en espacios de disenso, como pretendería Habermas (1973); al contrario, en su ambivalente interpretación, incluso de la misma categoría, como se expuso para el caso de la paz negativa, generó un proceso de polarización que eliminó las posiciones intermedias (como la paz imperfecta), haciendo de la disputa política, un combate irremediable sin lugar para la trasformación de conflictos (Galtung, 2003).

Los altos niveles de polarización política producidos por la opinión pública difundida por los medios masivos de comunicación son reflejo del enfrentamiento ideológico (Pan y Kosicki, 1993) que puede desencadenar un framing derivado de múltiples marcos interpretativos atados a interés privados. Además, exacerbó en el país conflictos políticos y sociales que hoy se traducen de nuevo en un proceso sistemático de exterminio contra líderes 
sociales de izquierda y el riesgo permanente de la perdida de lo acordado; esto en consonancia con la premisa ya planteada por Guzmán (2015) y también utilizada por Chavero y Castromil (2012) para el caso de las elecciones autónomas y municipales 2011 en España, que afirma que

el sistema mediático colombiano [o español para el caso de Castromil y Chavero (2012)] responde a las características del modelo pluralista polarizado (Hallin y Mancini, 2008), lo que, entre otras cosas, significa que históricamente la prensa y el poder político han mantenido una estrecha relación basada en la creación conjunta de un discurso público acorde a intereses particulares y afinidades partidistas. (Guzmán, 2015, p.11)

Cada partido de la Unidad por la Paz tenía un interés alrededor del tema de la paz y el plebiscito, ello pudo evidenciarse en la apuesta política que tenía Cambio Radical a diferencia del partido Alianza Verde, o la participación condicionada de los Conservadores frente a la posición del Partido de la U. Por su parte, el partido Liberal descargó todo su accionar en la figura que representaba el Expresidente Cesar Gaviria. En cuanto a movimientos políticos, cabe destacar el respaldo que realizó la Fuerza Ciudadana en la región Caribe, la estrategia de "La Paz Sí es Contigo" en cabeza de la Exsenadora Piedad Córdoba y el movimiento Marcha Patriótica; movimientos que poco o nada fueron visibilizados en este diario, como ocurrió con el partido Polo Democrático. De otro lado, al ser el Centro Democrático el único partido que abiertamente estuvo en oposición, esto le permitió ser necesariamente el llamado a sentar su posición como contraparte, posición respaldada en la favorabilidad que para el momento tenía el Expresidente Uribe.

El hecho de que cada partido político que respaldaba el Sí generaba su propia estrategia de campaña pudo confundir al electorado o defraudarlo; a pesar de que todos se enmarcaban en el frame paz negativa, sus estrategias no se conectaron con los votantes al estar concentradas en la pedagogía, la racionalidad y la apuesta por un futuro incierto; esto a diferencia de la campaña 
del NO que, como lo confesó abiertamente Juan Carlos Vélez (Gerente de la Campaña por el No) unos días después de haber ganado, efectivamente movilizó los sentimientos de los colombianos desde lo visceral, los motivó a votar "verracos" (El Colombiano, 6 de octubre de 2016), es decir, hicieron uso de las emociones políticas como mecanismo privilegiado para movilizar la intención de voto.

En síntesis, los líderes políticos, en su rol de "iluminar" (Saroti, 2009) sobre los asuntos públicos, adecuaron los marcos interpretativos de la paz a sus intereses electorales, generaron estructuras y valores cimentados en formas coercitivas de consenso, sobre las cuales en 2018 soportaron sus apuestas electorales, cercenando el lugar del dialogo intersubjetivo por el que abogaban las subregiones del país en la búsqueda de la paz. Esto se hizo evidente en el hecho de que en ninguna de las noticias se encontró alusión directa a la guerrilla de las FARC o a la opinión de alguno de sus integrantes frente a este proceso democrático.

\section{Referencias}

Acosta, R., Brunet, M., y Córdoba, J. (2017). La calidad de la información periodística de elespectador.com. El caso del Plebiscito por la Paz, 2016 en Colombia. Revista Latina de Comunicación Social, 72, 1.502-1.514. DOI: 10.4185/RLCS-2017-1231

Basset, Y. (2018). Claves del rechazo del plebiscito para la paz en Colombia. Estudios Políticos, 52, 241-265. http://doi.org/10.17533/udea.espo.n52a12

Bateson, G. (1972). Steps to an Ecology of Mind: Collected Essays in Antropology, Psychiatry, Evolution and Epistemology. New York: Ballantine Books. 
Berger, P. \& Luckmann, T. (1982). La construcción social de la realidad. Buenos Aires: Amorrortu.

Botero, S. (2017). El plebiscito y los desafíos políticos de consolidar la paz negociada en Colombia. Revista de ciencia política (Santiago), 37(2), 369-388. https://dx.doi.org/10.4067/s0718-090x2017000200369

Bourdieu. P. (1992). La opinión pública no existe. Debates en Sociologia, 17, 301-311. file:///C:/Users/pvalencia/Downloads/6673-Texto\%20del\%20art \%C3\%ADculo-25865-1-10-20130722.pdf

Boutros-Ghali, B. (1992). An Agenda for Peace. New York: United Nations. Recuperado de: http://www.un-documents.net/a47-277.htm

Calderón, J. (2014). La cobertura informativa de los medios de comunicación frente al conflicto armado y el proceso de paz en Colombia: responsabilidad frente a la divulgación de la noticia. Ciudad Paz-Ando, 7(2), 92-112. https://doi.org/10.14483/udistrital.jour.cpaz.2014.2.a05

Cárdenas, J. D. (2013). Los Medios De Comunicación Como Actores (Des) Legitimadores. Algunas Reflexiones Acerca del Rol de los Medios de Comunicación sobre la Construcción de la Opinión Pública En Torno Al Proceso De Paz De La Habana. Análisis Político, 28(85), 38-56. http://dx.doi.org/10.15446/anpol.v28n85.56245

Cardona-Zuleta, L. y Londoño-Álvarez, C. (2018). La retórica del miedo como estrategia política. El plebiscito por la paz en Colombia. Forum. Revista Departamento de Ciencia Política, 14, 43-68. https://revistas.unal.edu.co/ index.php/forum/article/view/69614

Córdoba, I. (1 de jun de 2017) Cartillas y plebiscito, dos ejemplos de postverdad. Directo Bogotá, https://www.directobogota.com/post/2017/06/01/cartillasy-plebiscito-dos-ejemplos-de-postverdad 
Chavero, Palmira \& Castromil, Antón. (2012). Polarización política y negativismo mediático. Similitudes y diferencias en la prensa de derecha y la de izquierda en las elecciones autonómicas y municipales de 2011. REDMARKA Revista Digital de Marketing Aplicado, 5(8), 55-81. https://eprints.ucm.es/43609/

D'Angelo, P. (2002). News Framing as a Multiparadigmatic Research Program: A Response to Entman. Journal of Communication, 52, 870-888. https://doi.org/10.1111/j.1460-2466.2002.tb02578.x

El Colombiano. (s.f.). "Estábamos buscando que la gente saliera a votar verraca": Juan C. Vélez. El Colombiano. https:/www.elcolombiano.com/ colombia/acuerdos-de-gobierno-y-farc/entrevista-a-juan-carlos-velezsobre-la-estrategia-de-la-campana-del-no-en-el-plebiscito-CE5116400

El Espectador. (19 de julio de 2016). El plebiscito se convocará cuando se firme el acuerdo final. El Espectador. http://www.elespectador.com/ noticias/politica/el-uribismo-frente-al-plebiscito-entre-el-no-y-abstenciarticulo-644174

El Espectador. (19 de julio de 2016). 15 claves para entender el plebiscito por la paz, El Espectador. https://www.elespectador.com/noticias/judicial/15claves-entender-el-plebiscito-paz-articulo-644263

El Espectador. (21 de julio de 2016). Eslogan de la U para promover el Plebiscito. El Espectador. https://www.elespectador.com/noticias/politica/ si-paz-no-guerrilla-el-eslogan-de-u-promover-el-plebisc-articulo-644621

El Espectador. (25 de julio de 2016). "Sí a la vida", la campaña de Mockus para votar "Sí" en el plebiscito por la paz". El Espectador. http://www. elespectador.com/noticias/politica/si-vida-campana-de-mockus-votar-siel-plebiscito-paz-articulo-645342 
El Espectador. (28 de julio de 2016). Pastrana invita al conservatismo a votar $\mathrm{NO}$ en el plebiscito por la paz. El Espectador. https://www.elespectador. com/noticias/paz/pastrana-invita-al-conservatismo-decir-no-plebiscito-paarticulo-645871

El Espectador. (1 de agosto de 2016). Gobernadores anuncian respaldo a la campaña del SI al plebiscito por la paz. El Espectador. http://www. elespectador.com/noticias/politica/gobernadores-anuncian-respaldocampana-del-si-al-plebis-articulo-646667

El Espectador. (3 de agosto de 2016). Votar no al plebiscito es votar por la guerra: Gaviria a Uribe. EL Espectador. http://www.elespectador.com/noticias/ politica/votar-no-al-plebiscito-votar-guerra-gaviria-uribe-articulo-647151

El Espectador. (5 de agosto de 2016). Álvaro Uribe y Claudia López, abucheados en campaña por el plebiscito por la paz. El Espectador. https://www.elespectador.com/noticias/nacional/alvaro-uribe-y-claudialopez-abucheados-campana-el-pleb-articulo-647581

El Espectador. (10 de agosto 2016). La propuesta para un plebiscito digital. El Espectador. https://www.elespectador.com/noticias/politica/propuestaun-plebiscito-digital-articulo-648438

El Espectador. (10 de agosto de 2016). Académicos, por el sí al plebiscito. El Espectador. https://www.elespectador.com/noticias/politica/academicosel-si-el-plebiscito-articulo-648447

El Espectador. (18 de agosto de 2016). La iglesia católica aclara su posición frente al plebiscito por la paz. El Espectador. https://www.elespectador.com/ noticias/politica/iglesia-catolica-aclara-su-posicion-frente-al-plebiscitarticulo-649730 
El Espectador. (4 septiembre de 2016). Bogotá pedalea por el "Sí" al Plebiscito. El Espectador. https://www.elespectador.com/noticias/bogota/bogotapedalea-el-si-el-plebiscito-articulo-653022

El Espectador. (5 de septiembre de 2016). Centro Democrático Solicitó al Concejo de Estado Suspender el Plebiscito. El Espectador. http://www. elespectador.com/noticias/judicial/centro-democratico-le-solicito-alconsejo-de-estado-sus-articulo-653160

El Espectador. (5 de septiembre de 2016). Se inicia campaña en la Costa Caribe por el Sí al Plebiscito. El Espectador. https://www.elespectador. com/noticias/politica/se-inicia-campana-costa-caribe-el-si-al-plebiscitoarticulo-653030

El Espectador. (26 de septiembre de 2016). "Están utilizando la paz como excusa para imponer la ideología de género": Exprocurador Ordóñez. El Espectador. https://www.elespectador.com/noticias/judicial/estan-utilizando-la-pazcomo-excusa-para-imponer-la-ideologia-de-genero-exprocurador-ordonez/

El Espectador. (30 de septiembre de 2016). Radican solicitud ante la Corte Constitucional para suspender el plebiscito por la paz. El Espectador. https://www.elespectador.com/noticias/judicial/radican-solicitud-corteconstitucional-suspender-el-ple-articulo-657759

El Espectador. (1 de octubre de 2016). "Cada colombiano tendrá el mismo poder que el Presidente de decir Sí o No": Santos. El Espectador. https://www.elespectador.com/noticias/paz/cada-colombiano-tendra-elmismo-poder-el-presidente-de-articulo-658013

El Espectador. (1 de octubre de 2016). El No también es la defensa de la paz. El Espectador. https://www.elespectador.com/noticias/politica/el-notambien-defensa-de-paz-ivan-duque-articulo-657964 
El Espectador. (6 de octubre de 2016). La cuestionable estrategia de campaña del No. El Espectador. https://www.elespectador.com/noticias/politica/lacuestionable-estrategia-de-campana-del-no/

Entman, R. M. (1993): Framing: Toward Clarification of a Fractured Paradigm. Journal of Communication, 43, 51-58. https://doi.org/10.1111/ j.1460-2466.1993.tb01304.x

Entman, R. M. (2003). Cascading Activation: Contesting the White House's Frame After 9/11. Political Communication, 20, 415-422.

Entman, R. M. (2007). Framing Bias: Media in the Distribution of Power. Journal of Communication, 57, 163-173. https://doi.org/10.1111/j.14602466.2006.00336.x

Farias, P. (1999). La prensa y las transiciones políticas a la democracia. Comunicar, 13, 71-77. https://doi.org/10.3916/25280

Galtung, J. (2003). Paz por medios pacíficos. Paz y conflicto, desarrollo y civilización. Gernika: Gernika Gogoratuz.

Gitlin, T. (1980). The Whole World is Watching. Berkeley: University of California Press.

Goffman, E. (1986). Frame Analysis. An Essay on the Organization of Experience, Northeastern. Boston: University Press.

Guzmán, I. (2015). Framing aplicado: los encuadres mediáticos durante la campaña electoral presidencial de Colombia 2014 [Tesis de doctorado, Universidad Complutense]. https://eprints.ucm.es/42062/1/T38623.pdf

Habermas, J. (1973). Öffentlichkeit (ein Lexikonartikel). En Kultur und Kritik, verstreute Aufsätze (p. 61). Francfort: Suhrkamp,

Habermas, J. (1981). Historia y crítica de la opinión pública. La transformación estructural de la vida pública. Barcelona: Gustavo Gili. 
Janowitz, M. (1994) Los medios de comunicación de masas. Revista Española de la Opinión Pública. Tomo la cita del trabajo realizado por MONTABES, J. Los parlamentos de papel en el caso español. Prensa y Transición democrática, Madrid, Iberoamericana; 42-67.

Jiménez, J. (28 de agosto de 2016). Castrochavismo, gais y paz. El Espectador. https://www.elespectador.com/noticias/el-mundo/castrochavismo-gais-ypaz/

Lakoff, G. (2008). The Political Mind. New York: Penguin.

Muñoz, F. (1998). (pp.191-228) Granada: Editorial Universidad de Granada.

Muñoz, F. (s.f.) La paz imperfecta [Archivo PDF]. http://www.ugr.es/ eirene/ eirene/Imperfecta.pdf

Palacios, M. y Serrano, M. (2010). Colombia y México: las violencias del narcotráfico. En: A. Alvarado y M. Serrano (Coord.), Seguridad nacional y seguridad interior (106-149). Ciudad de México: El Colegio de México.

Pan, Z. y Kosicki, G. (1993). Framing Analysis: An Approach to News Discourse. Political Communication, 10(1), 55-75. https://doi.org/10.1080/10584609. 1993.9962963

Paris, R. (2005). At War's End. Building Peace After Civil Conflict. Cambridge: Cambridge University Press.

Perilla, D. (2018). La plebitusa: movilización política de las emociones posplebiscito por la paz en Colombia. Maguaré, 32(2), 153-181. https://doi.org/10.15446/mag.v32n2.77012

Ramírez, J. (4 de octubre de 2016). El No ha sido la campaña más barata y más efectiva de la historia. La República. https://www.asuntoslegales.com. co/actualidad/el-no-ha-sido-la-campana-mas-barata-y-masefectiva-de-lahistoria-2427891 
Reese, S. D. (2001). Framing Public Life: A Bridging Model for Media Research.

En S. D. Reese, O. Gandy \& A. Grant (eds.), Framing Public Life. Perspectives on Media and Our Understanding of the Social World (pp. 7-31). Mahwah: Lawrence.

Richard, E., \& Saffon, S. (2016). La paz en el visor mediático: el framing del noticiero sobre los diálogos de paz durante la campaña presidencial colombiana. Más Poder Local, (26), 36-50. https://dialnet.unirioja.es/ servlet/articulo?codigo $=5569523$

Richmond, P. O. (2011). Resistencia y paz postliberal. Relaciones Internacionales, (16), 13-45. https://revistas.uam.es/relacionesinternacionales/article/view/5062

Ríos, I., Pérez, M., \& Morillo, S. (2018). La agenda setting en la red social Facebook: Campaña del plebiscito por la paz en Colombia. Revista Kepes, 15(17), 93-117. 10.17151/kepes.2018.15.17.5

Sádaba, T. (2001). Origen, aplicación y límites de la "teoría del encuadre" (framing) en comunicación. Comunication and Society, 14(2), 143-175. https://www.unav.es/fcom/communication-society/es/articulo.php?art_ $\mathrm{id}=335$

Sádaba, T., Rodriguez, J., y Castro, M. (2012). Propuesta de sistematización de la teoría del framing para el estudio y praxis de la comunicación política. Observatorio (OBS*) Journal, 6(2), 109-126. https://dialnet.unirioja.es/ servlet/articulo? codigo $=5577051$

Sartori, G. (2009). La democracia en 30 lecciones. Madrid: Taurus.

Semana. (5 de agosto de 2017). "Hacer trizas" el acuerdo con las FARC: ¿es posible? Revista Semana. https:/www.semana.com/nacion/articulo/ uribismo-hara-trizas-acuerdo-acuerdo-con-farc-esta-blindado/524529 
Tankard, J. (2001). The Empirical Approach to the Study of Media Framing. En: S. Reese, O. H. Gandy Jr y A. Grant (eds.), Framing Public Life: Perspectives on Media and Our Understanding of the Social World (pp. 95-106). Nueva Jersey: Lawrence Erlbaum.

Tuchman, G. (1978). Making News. New York: Free Press.

Tuchman, G. (1983). La producción de la noticia. Barcelona: Ediciones G. Gili.

Valencia, P. y Ríos, O. (2020). El proceso de postacuerdo reflejado en el traslado de la agenda de la opinión pública en las elecciones 2018 en Colombia: ¿del peacebuilding al statebuilding? En. E. Natera y P. Valencia, Comunicación Política y Transiciones en América Latina: Opinión Pública y Democracia en el Centro del Debate (En prensa). Madrid: Tirando Lo Blanch.

Valera-Ordaz, L. y López-García, G. (2014). Agenda y marcos en las webs de PP y PSOE en la cibercampaña de 2011. Revista Latina de Comunicación Social, 69, 41-66. 10.4185/RLCS-2014-1000

Van Gorp, B. (2007). The Constructionist Approach to Framing: Bringing Culture Back In. Journal of Communication, 57, 60-78. https://doi.org/10.1111/ j.0021-9916.2007.00329.x

Como citar: Valencia-Londoño, P. A. y Muñoz-Giraldo, O. I. (2020). El framing (encuadre) de los líderes políticos durante el "Plebiscito por la Paz" en Colombia ¿Preparando la opinión pública para las elecciones 2018? Revista KEPES, 17(22), 193-228. https://doi.org/10.17151/kepes.2020.17.22.8 